\title{
Área foliar específica e anatomia foliar quantitativa do capim-braquiária e do amendoim-forrageiro submetidos a sombreamento
}

\author{
Kátia Fernanda Gobbi ${ }^{1}$, Rasmo Garcia ${ }^{1}$, Marília Contin Ventrella ${ }^{2}$, Américo Fróes \\ Garcez Neto ${ }^{1}$, Gabriel Cipriano Rocha ${ }^{1}$
}

1 Departamento de Zootecnia/UFV.
2 Departamento de Biologia Vegetal/UFV.

RESUMO - A área foliar específica e as características anatômicas foliares da braquiária (Brachiaria decumbens cv. Basilisk) e do amendoim-forrageiro (Arachis pintoi cv. Amarillo) foram avaliadas em resposta a níveis de sombreamento artificial $(0,50$ e 70\%), com o objetivo de se determinar a aclimatação destas forrageiras às modificações no ambiente luminoso. Utilizou-se o delineamento em blocos completamente casualizados, com três repetições. Foram realizados três e dois cortes, respectivamente, para avaliação das plantas de braquiária e amendoim-forrageiro. A área foliar específica das duas espécies aumentou linearmente em função do incremento nos níveis de sombra. Na braquiária, o aumento da área foliar específica foi acompanhado por redução linear na espessura da folha, com os níveis crescentes de sombra. Já a espessura das folhas de amendoim-forrageiro não sofreu alteração significativa com o sombreamento crescente. A densidade estomática nas faces adaxial e abaxial das folhas do amendoim-forrageiro e da braquiária diminuiu linearmente com o incremento nos níveis de sombra. Apesar do aumento na proporção de espaços intercelulares nas folhas de amendoim-forrageiro, a área ocupada pelos diferentes tecidos não foi afetada significativamente pelos níveis de sombra. As folhas de braquiária apresentaram aumento quadrático na área ocupada pela bainha do feixe vascular, no primeiro corte. A área ocupada pelos feixes vasculares e pelas células buliformes foi reduzida no segundo e terceiro cortes, respectivamente, com o sombreamento crescente. As espécies estudadas apresentaram boa aclimatação às variações na intensidade luminosa, e são boas alternativas para utilização em ambientes com baixos níveis de irradiância.

Palavras-chave: Arachis pintoi, Brachiaria decumbens, densidade estomática, luminosidade, tecidos foliares

\section{Specific leaf area and quantitative leaf anatomy of signalgrass and forage peanut submitted to shading}

\begin{abstract}
Specific leaf area and leaf anatomy traits of signalgrass (Brachiaria decumbens cv. Basilisk) and forage peanut (Arachis pintoi cv. Amarillo) were evaluated in response to levels of artificial shades (0,50 and $70 \%)$ with the objective of determining the acclimation of these forage species to changes in the luminous environment. It was used a complete random block design, with three replicates. Three and two harvests were performed for evaluation of signalgrass and forage peanut, respectively. Specific leaf blade of the two species increased linearly as a function of the increasing levels of shading. In signalgrass, the increase on specific leaf area was followed by a linear reduction in leaf thickness, with the increasing levels of shade. On the other hand, forage peanut leaf thickness was not significantly altered by shade. Stomatal density on adaxial and abaxial leaf surfaces decreased linearly with the increase on levels of shade. In spite of increase of the proportion on intercellular spaces in forage peanut leaves, the area occupied by different tissues was not significantly affected by shade levels. Signal grass leaves presented a quadratic increase in the area occupied by the vascular bundle sheath in the first harvest. The area occupied by vascular bundle and by bulliform cells was reduced in the second and third harvest, respectively, with the increasing shade. The forage species evaluated showed a good acclimation to variations on light intensities, and they are good alternatives to use in environments with low solar radiation levels.
\end{abstract}

Key Words: Arachis pintoi, Brachiaria decumbens, leaf tissues, luminosity, stomatal density

\section{Introdução}

Um dos principais obstáculos no manejo de sistemas silvipastoris é a alteração do ambiente de crescimento das espécies que constituem o sub-bosque. A sombra criada pelas árvores promove modificações significativas no microclima, podendo afetar a morfologia (Lin et al., 2001), anatomia (Allard et al., 1991) e composição química das 
plantas forrageiras (Kephart \& Buxton, 1993), o que por sua vez pode ter efeito sobre o crescimento, produção e qualidade das plantas.

A exploração bem sucedida dos sistemas silvipastoris requer o uso de espécies forrageiras tolerantes às condições de baixa luminosidade, apresentando adaptações que garantam sua sobrevivência e produção satisfatória nestes ambientes.

As plantas sombreadas investem, relativamente, maior proporção de fotoassimilados no aumento da área foliar, para maximizar a captação da luz disponível. Geralmente possuem folhas delgadas, maior área foliar específica (AFE) e folhas com menor densidade de massa (Lambers et al., 1998).

As alterações anatômicas que ocorrem nas folhas que se desenvolvem sob baixa luminosidade têm papel importante na adaptação da planta às condições impostas pelo ambiente. Geralmente estas alterações estão relacionadas com o aumento da captação e aproveitamento da luz incidente, recurso que limita o crescimento na sombra, aumentando a eficiência fotossintética da planta (Lambers et al., 1998).

O aumento da AFE em condições de baixa luminosidade está diretamente relacionado com as alterações anatômicas que podem ocorrer nas plantas sombreadas como, cutículas e epiderme mais delgadas, menor espessura de mesofilo e menor proporção de parênquima paliçádico, de tecidos condutores e de sustentação, maior proporção de espaços intercelulares e menor densidade estomática (Berlyn \& Cho, 2000).

A avaliação do tipo e magnitude das alterações fisiológicas, anatômicas e morfológicas que ocorrem na planta sob irradiância reduzida pode contribuir para a seleção de espécies forrageiras adequadas, bem como para a adoção de técnicas de manejo compatíveis para obtenção de forragem de qualidade e manutenção da sustentabilidade do sistema produtivo.

Conduziu-se este estudo com o objetivo de avaliar a área foliar específica e as características anatômicas quantitativas das folhas de Brachiaria decumbens cv. Basilisk e de Arachis pintoi cv. Amarillo submetidos a três níveis de sombra artificial.

\section{Material e Métodos}

O ensaio experimental foi conduzido no setor de agrostologia do Departamento de Zootecnia, na Universidade Federal de Viçosa, em Viçosa, Minas Gerais, Brasil, no período de dezembro de 2005 a junho de 2006. As análises laboratoriais foram realizadas no laboratório de Forragicultura do Departamento de Zootecnia e no laboratório de Anatomia Vegetal do Departamento de Biologia Vegetal/UFV.
O município de Viçosa está localizado na região da Zona da Mata de Minas Gerais, numa altitude de $651 \mathrm{~m}$ acima do nível do mar, com $20^{\circ} 45^{\prime} 40^{\prime \prime}$ de latitude sul e $42^{\circ} 52^{\prime} 40^{\prime \prime}$ de longitude oeste. O clima, segundo classificação de Köppen, é do tipo Cwa. A precipitação média anual é de $1.221 \mathrm{~mm}$ caracterizada por uma distribuição estacional, com estações seca e chuvosa bem definidas.

Neste estudo, foram utilizadas duas espécies forrageiras, uma gramínea e uma leguminosa, em monocultivo. A gramínea avaliada foi o capim-braquiária (Brachiaria decumbens Stapf. cv. Basilisk), e a leguminosa o amendoimforrageiro (Arachis pintoi Krapov. \& Gregory cv. Amarillo).

Os tratamentos foram definidos por três níveis de sombreamento artificial, de acordo com o delineamento em blocos completamente casualizados, com três repetições. Os níveis de sombreamento artificial foram: 0 (pleno sol), 50 e $70 \%$. Os níveis de 50 e $70 \%$ foram obtidos por meio de estruturas de sombreamento artificial, dispostas no campo sobre as parcelas experimentais $\left(4 \mathrm{~m}^{2}\right)$.

As estruturas de sombreamento, com 1,10 m de altura, foram construídas com seis estacas de madeira, sobre as quais foi colocada uma armação retangular feita com tubos de PVC, sendo cobertas por telas pretas de polipropileno (sombrite) permitindo $50 \%$ de transmissão luminosa (sombrite $50 \%$ ) e $30 \%$ de transmissão luminosa (sombrite $70 \%)$. Cada estrutura de sombreamento $(4 \times 2 \mathrm{~m})$ foi montada sobre duas parcelas experimentais, uma com gramínea e outra com leguminosa, cultivadas lado a lado. As telas de sombrite foram presas nas estruturas, obtendo-se uma fração excedente de tela nas laterais, visando impedir a penetração de luz direta nas parcelas nos horários de menor ângulo da luz solar incidente, como no início da manhã e final da tarde. Estas frações excedentes foram presas de forma que em uma das laterais da estrutura fosse possível a abertura e remoção parcial do sombrite, permitindo-se os tratos culturais e a coleta de dados nas parcelas.

Antes da delimitação das unidades experimentais e montagem das estruturas de sombreamento foi feito um corte de rebaixamento e uniformização da braquiária que já estava estabelecida na área, utilizando-se roçadeira costal motorizada. Na sequência, a área das parcelas foi delimitada utilizando-se estacas de madeira.

As parcelas destinadas à leguminosa foram preparadas para semeadura com aplicação de herbicida à base de glifosato, visando eliminar todas as plantas existentes na área. Em seguida o solo foi preparado manualmente com o uso de enxadas.

O amendoim-forrageiro foi semeado em 21 de dezembro de 2005. A semeadura foi feita em sulcos de aproximadamente três centímetros de profundidade e com espaçamento de 
$20 \mathrm{~cm}$ entre sulcos, utilizando-se $20 \mathrm{~kg}$ de sementes por hectare. No sulco de plantio foram aplicados $100 \mathrm{~kg} / \mathrm{ha} \mathrm{de}$ $\mathrm{P}_{2} \mathrm{O}_{5}$, na forma de superfosfato simples. As parcelas foram irrigadas diariamente, garantindo condições favoráveis para germinação das sementes. Após a germinação e emergência do amendoim-forrageiro foram montadas as estruturas de sombreamento dentro de cada bloco, sobre as respectivas parcelas da gramínea e da leguminosa.

Um segundo corte de uniformização foi realizado na gramínea em 27 de janeiro de 2006 para início do período experimental. Após o corte foi feita a adubação de cobertura, aplicando-se nas parcelas $50 \mathrm{~kg} / \mathrm{ha}$ de nitrogênio, na forma de sulfato de amônio. Foram aplicados ainda $100 \mathrm{~kg}$ de $\mathrm{P}_{2} \mathrm{O}_{5} /$ ha e $70 \mathrm{~kg}$ de $\mathrm{K}_{2} \mathrm{O} / \mathrm{ha}$, na forma de superfosfato simples e cloreto de potássio, respectivamente. Nas parcelas da leguminosa a adubação de cobertura foi feita apenas com potássio ( $70 \mathrm{~kg}$ de $\mathrm{K}_{2} \mathrm{O} / \mathrm{ha}$ ), uma vez que o fósforo já havia sido aplicado nos sulcos na semeadura. Após cada corte para avaliação das plantas houve adubação de cobertura nas parcelas. As doses de adubo utilizadas foram calculadas em função de análise de solo realizada previamente.

O período de avaliação das plantas foi dividido em ciclos de crescimento, sendo que cada ciclo foi concluído com o corte das plantas. Durante os ciclos de crescimento, as plantas de todos os tratamentos foram monitoradas quanto à interceptação de luz pelo dossel. Para avaliação da interceptação luminosa nas parcelas utilizou-se o sensor linear LI - 191SA, de um metro de comprimento, acoplado a um medidor de luz LI - 250, ambos da marca LI-COR com o qual foram feitas leituras da radiação fotossinteticamente ativa (RFA) tanto acima (uma leitura) quanto na base do dossel (cinco leituras). O percentual de interceptação luminosa foi calculado como a quantidade de RFA interceptada (RFA acima do dossel menos aquela na base do dossel) dividida pela RFA acima do dossel, e multiplicando-se o resultado por 100. As leituras foram realizadas em intervalos semanais, sem as coberturas de sombreamento, no horário de meio-dia, em dias de céu claro. Quando a interceptação luminosa das plantas se aproximava dos 95\% (IAF crítico) da luz incidente as leituras eram feitas diariamente.

A interceptação luminosa do dossel foi utilizada como critério para corte das plantas. Quando a interceptação luminosa das plantas de um dos tratamentos atingia o valor médio de $95 \%$ da luz solar incidente efetuava-se a coleta de material vegetal para avaliações laboratoriais. Para a Brachiaria decumbens foram realizados três cortes de avaliação, 25 de fevereiro, 26 de março e 16 de junho/2006, que corresponderam ao primeiro, segundo e terceiro cortes, respectivamente. Já o Arachis pintoi, foi submetido a dois cortes, o primeiro no dia 23 de março e o segundo no dia 13 de maio de 2006.

Após as coletas para avaliações laboratoriais, as plantas de todas as parcelas foram submetidas a corte de uniformização a uma altura de dez e três centímetros acima do nível do solo, respectivamente, para gramínea e leguminosa.

Para determinação da área foliar específica da gramínea, coletou-se uma amostra de 10 perfilhos por parcela, cortados ao nível do solo. Todas as lâminas foliares foram removidas dos perfilhos e os valores de área foliar determinados por meio de um medidor de área foliar da marca Delta-T Devices Ltda, no Laboratório de Forragicultura do Departamento de Zootecnia/UFV. Após medição da área foliar as lâminas foram levadas para estufa a $65^{\circ} \mathrm{C}$ por 72 horas determinando-se seu peso seco. Para a leguminosa, foram colhidas 20 folhas (4 folíolos/folha) por parcela. Todos os folíolos foram destacados e feita a medição da área foliar. Na sequência, os folíolos foram levados para estufa para determinação do peso seco.

Para as avaliações anatômicas das espécies, foram coletadas duas lâminas foliares (gramínea) e duas folhas com quatro folíolos cada (leguminosa) por parcela. $\mathrm{Na}$ gramínea, coletou-se a folha mais jovem completamente expandida presente no perfilho e, na leguminosa, a folha mais jovem e completamente desenvolvida da planta principal.

A porção mediana das folhas de ambas as espécies foi cortada em segmentos de aproximadamente $1 \mathrm{~cm}$ de comprimento, sendo estes fixados em $\mathrm{FAA}_{50}$ (formaldeído: ácido acético glacial: etanol, 5:5:90), por 48 horas (Johansen, 1940). Em seguida, as amostras foram retiradas da solução fixadora, lavadas e armazenadas em solução de etanol 70\% (Johansen, 1940). Para confecção das lâminas permanentes, porções da folha foram desidratadas em série etílica e incluídas em historesina (metacrilato). Seções transversais de folha, com $5 \mu \mathrm{m}$ de espessura, foram dispostas sobre lâminas histológicas, coradas com azul de toluidina ( $\mathrm{O}^{\prime}$ Brien et al., 1964), e a montagem feita com Permount.

Para determinação da densidade estomática nas faces adaxial e abaxial das lâminas foliares, utilizou-se a técnica de diafanização (Handro, 1964, modificado), onde porções de folha de aproximadamente $1 \mathrm{~cm}^{2}$ foram clarificadas utilizando-se hipoclorito de sódio a $20 \%$, coradas com violeta cristal e a montagem das lâminas feita com Permount.

Foram obtidas imagens digitalizadas do material contido nas lâminas, através de um fotomicroscópio Olympus AX70. Essas imagens foram avaliadas utilizando-se o programa computacional Image-Pro Plus 4.5.

A contagem de estômatos nas faces adaxial e abaxial da folha foi feita utilizando-se dez campos de área conhecida 
por folha, evitando-se a região da nervura central e das margens da folha.

Nas imagens de seção transversal das laminas foliares de Brachiaria decumbens foram avaliadas a espessura da folha, área total da seção transversal e proporção de epiderme adaxial (\%EAD), epiderme abaxial (\%EAB), células buliformes $(\% \mathrm{CB})$, bainha do feixe vascular $(\% \mathrm{BFV})$, esclerênquima (\%ESC), feixe vascular $(\% \mathrm{FV})$ e mesofilo (\%MES). Nas seções transversais das folhas de Arachis pintoi avaliou-se a espessura da folha, espessura dos parênquimas paliçádico e lacunoso, distância entre feixes vasculares, área total da seção transversal e proporção de epiderme adaxial (\%EAD), epiderme abaxial (\%EAB), feixe vascular $(\% \mathrm{FV})$, espaços intercelulares $(\% \mathrm{EIC})$ e mesofilo (\%MES).

Os dados da gramínea e da leguminosa foram analisados separadamente. Os resultados obtidos foram interpretados estatisticamente por meio de análises de variância e de regressão. Os modelos que melhor explicaram o comportamento das variáveis foram escolhidos com base no coeficiente de determinação ajustado; pela significância da regressão, testada pelo teste F; pela significância dos coeficientes de regressão, testada pelo teste " $t$ ", com nível de significância aceitável de até $5 \%$ de probabilidade.

A análise estatística dos dados foi realizada utilizando-se os procedimentos GLM (General Linear
Models) e REG disponíveis no pacote estatístico SAS (SAS, 1990).

\section{Resultados e Discussão}

A área foliar específica (área de folha $\left(\mathrm{cm}^{2}\right) /$ massa de folha $(\mathrm{g}))$ do amendoim-forrageiro e da braquiária aumentou significativamente e de forma linear $(\mathrm{P}<0,05)$ em função do incremento nos níveis de sombra, em todos os cortes avaliados (Tabelas 1 e 2). Em média o aumento foi de 18 e $25 \%$ nas plantas de amendoim-forrageiro e de 34 e $41 \%$ na braquiária, sob 50 e $70 \%$ de sombra, respectivamente.

Allard et al. (1991) também observaram aumento linear na área foliar específica (AFE) da gramínea $\mathrm{C}_{3}$ Festuca arundinacea submetida a diferentes níveis de sombra. No trabalho de Lin et al. (2001), as espécies forrageiras avaliadas apresentaram aumento significativo na AFE, quando se desenvolveram sob 50\% de sombra, em relação às plantas que se desenvolveram a pleno sol.

Em condições de baixa irradiância, as plantas investem relativamente maior proporção de fotoassimilados e outros recursos no aumento da área foliar, apresentando maior AFE e folhas com menor densidade de massa. Geralmente estas alterações têm por objetivo aumentar a captação da luz incidente, aumentando a eficiência fotossintética da planta (Lambers et al., 1998).

Tabela 1 - Área foliar específica e características anatômicas de folhas de amendoim-forrageiro submetido a três níveis de sombreamento

\begin{tabular}{|c|c|c|c|c|}
\hline \multirow[t]{2}{*}{ Variável } & \multicolumn{2}{|c|}{ Sombreamento (\%) } & \multirow[t]{2}{*}{ Regressão } & \multirow{2}{*}{$\begin{array}{c}\text { Coeficiente de } \\
\text { variação }(\%)\end{array}$} \\
\hline & 50 & 70 & & \\
\hline
\end{tabular}

Corte 1

Área foliar específica $\left(\mathrm{cm}^{2} / \mathrm{g}\right)$

Estômatos epiderme adaxial $/ \mathrm{mm}^{2}$

Estômatos epiderme abaxial $/ \mathrm{mm}^{2}$

Espessura folha $(\mu \mathrm{m})$

Espessura parênquima paliçádico $(\mu \mathrm{m})$

Espessura parênquima lacunosos $(\mu \mathrm{m})$

Epiderme adaxial (\%)

Epiderme abaxial (\%)

Mesofilo (\%)

Feixe vascular (\%)

Espaços intercelulares (\%)

Corte 2

Área foliar específica $\left(\mathrm{cm}^{2} / \mathrm{g}\right)$

Estômatos epiderme adaxial $/ \mathrm{mm}^{2}$

Estômatos epiderme abaxial $/ \mathrm{mm}^{2}$

Espessura folha $(\mu \mathrm{m})$

Espessura parênquima paliçádico $(\mu \mathrm{m})$

Espessura parênquima lacunoso $(\mu \mathrm{m})$

Epiderme adaxial (\%)

Epiderme abaxial (\%)

Mesofilo (\%)

Feixe vascular (\%)

Espaços intercelulares (\%)

$\begin{array}{cc}\mathrm{Y}=240,4729+0,7439 * x ; r^{2}=0,82 & 8,26 \\ \mathrm{Y}=315,9521-1,1844 * * * x ; r^{2}=0,89 & 6,48 \\ \mathrm{Y}=214,0453-0,7014 * x ; r^{2}=0,87 & 11,35 \\ \mathrm{~ns} & 6,26 \\ \mathrm{Y}=83,2177-0,2289 * * x ; r^{2}=0,94 & 2,38 \\ \mathrm{~ns} & 6,06 \\ \mathrm{~ns} & 9,55 \\ \mathrm{~ns} & 12,70 \\ \mathrm{~ns} & 8,70 \\ \mathrm{~ns} & 26,59 \\ \mathrm{Y}=10,3963+0,0594 * x ; r^{2}=0,63 & 11,71 \\ \mathrm{n}=214,5131+0,8993 * * * x ; r^{2}=0,99 & \\ \mathrm{Y}=338,4128-1,4511 * * * x ; r^{2}=0,86 & 3,50 \\ \mathrm{Y}=227,7128-0,8828 * * x ; r^{2}=0,79 & 6,45 \\ \mathrm{~ns} & 9,65 \\ \mathrm{Y}=71,4162-0,1100 * x ; r^{2}=0,86 & 6,61 \\ \mathrm{~ns} & 6,63 \\ \mathrm{~ns} & 8,65 \\ \mathrm{~ns} & 4,25 \\ \mathrm{~ns} & 3,53 \\ \mathrm{~ns} & 6,47 \\ \mathrm{Y}=6,7853+0,0773 * * x ; r^{2}=0,84 & 18,96 \\ \mathrm{n} & 10,73\end{array}$

8,26

11,35

6,26

6,06

9,55

(2)

6,59

13,3

$\begin{array}{ll}13,3 & 14,3 \\ 13,7 & 14,6\end{array}$

274,8

229,5

165,8

171,2

63,9

78,2

8,0

55,6

$\begin{array}{ccc}15,1 & 15,1 & 15,3 \\ 7,0 & 9,9 & 12,7\end{array}$

$\begin{array}{ccc}15,1 & 15,1 & 15,3 \\ 7,0 & 9,9 & 12,7\end{array}$

$* \mathrm{P}<0,05 ; * * \mathrm{P}<0,01 ; * * * \mathrm{P}<0,001$. ns $=$ não-significativo. 
Tabela 2 - Área foliar específica e características anatômicas de folhas de braquiária submetida a três níveis de sombreamento

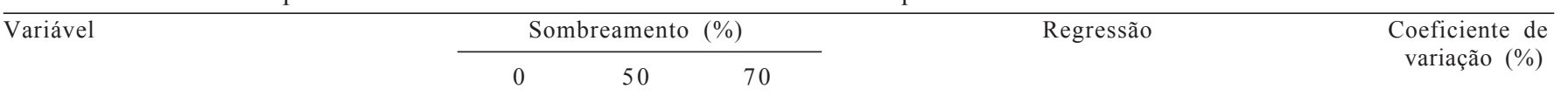

\section{Corte 1}

Área foliar específica $\left(\mathrm{cm}^{2} / \mathrm{g}\right)$

Estômatos epiderme adaxial $/ \mathrm{mm}^{2}$

Estômatos epiderme abaxial $/ \mathrm{mm}^{2}$

Espessura folha $(\mu \mathrm{m})$

Epiderme adaxial (\%)

Epiderme abaxial (\%)

Células buliformes (\%)

Mesofilo (\%)

Bainha do feixe vascular (\%)

Esclerênquima (\%)

Feixe vascular $(\%)$

Corte 2

Área foliar específica $\left(\mathrm{cm}^{2} / \mathrm{g}\right)$

Estômatos epiderme adaxial $/ \mathrm{mm}^{2}$

Estômatos epiderme abaxial $/ \mathrm{mm}^{2}$

Espessura folha $(\mu \mathrm{m})$

Epiderme adaxial (\%)

Epiderme abaxial (\%)

Células buliformes (\%)

Mesofilo (\%)

Bainha do feixe vascular (\%)

Esclerênquima (\%)

Feixe vascular $(\%)$

Corte 3

Área foliar específica $\left(\mathrm{cm}^{2} / \mathrm{g}\right)$

Estômatos epiderme adaxial $/ \mathrm{mm}^{2}$

Estômatos epiderme abaxial $/ \mathrm{mm}^{2}$

Espessura folha $(\mu \mathrm{m})$

Epiderme adaxial (\%)

Epiderme abaxial (\%)

Células buliformes (\%)

Mesofilo (\%)

Bainha do feixe vascular (\%)

Esclerênquima (\%)

Feixe vascular $(\%)$

$* \mathrm{P}<0,05 ; * * \mathrm{P}<0,01 ; * * * \mathrm{P}<0,001 . \mathrm{ns}=$ não-significativo

\begin{tabular}{|c|c|c|c|c|}
\hline 218,9 & 302,1 & 319,9 & $\mathrm{Y}=220,8860+1,4851 * * * x ; r^{2}=0,85$ & 3,42 \\
\hline 209,0 & 160,3 & 155,0 & $\mathrm{Y}=207,1171-0,8099 * * * x ; r^{2}=0,94$ & 6,99 \\
\hline 190,5 & 141,1 & 125,7 & $\mathrm{Y}=190,5154-0,9271 * * * x ; r^{2}=0,99$ & 4,27 \\
\hline 169,2 & 146,4 & 135,3 & $\mathrm{Y}=169,4995-0,4798 * \mathrm{x} ; \mathrm{r}^{2}=0,81$ & 9,77 \\
\hline 16,1 & 14,9 & 14,2 & ns & 10,10 \\
\hline 8,4 & 8,2 & 8,2 & $\mathrm{~ns}$ & 10,21 \\
\hline 12,8 & 11,6 & 11,0 & ns & 12,96 \\
\hline 40,3 & 36,9 & 39,0 & $\mathrm{~ns}$ & 4,30 \\
\hline 27,8 & 32,5 & 31,3 & $\mathrm{Y}=27,7700+0,2077 * * \mathrm{x}-0,0022 * \mathrm{x}^{2} ; \mathrm{R}^{2}=0,97$ & 3,80 \\
\hline 1,4 & 1,4 & 1,2 & ns & 14,16 \\
\hline 6,1 & 6,1 & 6,0 & ns & 6,64 \\
\hline 240,9 & 316,8 & 335,2 & $\mathrm{Y}=242,4154+1,3799 * * * x ; r^{2}=0,93$ & 3,42 \\
\hline 204,4 & 158,0 & 147,9 & $\mathrm{Y}=203,3470-0,8309 * * * x ; r^{2}=0,96$ & 6,43 \\
\hline 181,0 & 135,0 & 132,2 & $\mathrm{Y}=178,9598-0,7387 * * ; \mathrm{r}^{2}=0,76$ & 10,56 \\
\hline 162,1 & 135,3 & 124,3 & $\mathrm{Y}=162,1091-0,5391 * * * x ; \mathrm{r}^{2}=0,87$ & 3,75 \\
\hline 16,0 & 15,2 & 14,6 & ns & 10,48 \\
\hline 8,9 & 8,5 & 8,3 & ns & 5,51 \\
\hline 11,5 & 12,0 & 10,9 & ns & 12,43 \\
\hline 38,6 & 37,4 & 38,2 & ns & 7,27 \\
\hline 28,3 & 31,2 & 21,5 & ns & 7,07 \\
\hline 1,3 & 1,2 & 1,1 & ns & 12,97 \\
\hline 6,9 & 6,4 & 6,3 & $\mathrm{Y}=6,8933-0,0085 * \mathrm{x} ; \mathrm{r}^{2}=0,78$ & 5,09 \\
\hline 170,4 & 223,6 & 235,7 & $\mathrm{Y}=171,5978+0,9575 * * * x ; r^{2}=0,94$ & 4,36 \\
\hline 222,1 & 130,4 & 124,9 & $\mathrm{Y}=218,0983-1,4738 * * * x ; r^{2}=0,95$ & 10,58 \\
\hline 171,2 & 150,2 & 132,1 & $\mathrm{Y}=172,4359-0,5326^{* *} \mathrm{x} ; \mathrm{r}^{2}=0,79$ & 11,14 \\
\hline 149,5 & 105,9 & 104,4 & $\mathrm{Y}=147,4834-0,6885 * * x ; r^{2}=0,86$ & 7,23 \\
\hline 19,3 & 18,4 & 18,1 & ns & 5,83 \\
\hline 11,3 & 9,3 & 10,8 & ns & 8,13 \\
\hline 16,6 & 13,0 & 14,4 & $\mathrm{Y}=16,5933-0,1724 * * \mathrm{x}+0,0020 * \mathrm{x}^{2} ; \mathrm{R}^{2}=0,95$ & 6,97 \\
\hline 34,5 & 31,5 & 32,6 & ns & 8,03 \\
\hline 27,7 & 31,5 & 29,4 & ns & 7,09 \\
\hline 1,4 & 1,5 & 1,3 & ns & 35,55 \\
\hline 5,7 & 7,8 & 7,6 & ns & 13,77 \\
\hline
\end{tabular}

De acordo com Evans \& Poorter (2001), o aumento da AFE é o fator mais importante na maximização do ganho de carbono por unidade de massa foliar, sob condições de baixa luminosidade.

O aumento da AFE geralmente implica na redução da espessura da folha (Björkmann, 1981; Lambers et al., 1998). Nas folhas de braquiária, o aumento da AFE foi acompanhado por redução linear $(\mathrm{P}<0,05)$ na espessura da folha, com os níveis crescentes de sombra. Já a espessura das folhas de amendoim-forrageiro não sofreu alteração significativa com o sombreamento (Tabelas 1 e 2; Figura 1).

Apesar da não-alteração na espessura total das folhas, no amendoim-forrageiro a espessura do parênquima paliçádico diminuiu linearmente $(\mathrm{P}<0,05)$ com o sombreamento crescente. Por outro lado, a espessura do parênquima lacunoso não foi alterada pelos tratamentos (Tabela 1).
Assim, a proporção de parênquima lacunoso aumentou em relação ao mesofilo total (parênquima paliçádico + parênquima lacunoso), nas folhas sombreadas.

Segundo Lambers et al. (1998), a espessura do parênquima lacunoso é similar quando se compara folhas de sol e de sombra, enquanto que a espessura do parênquima paliçádico geralmente é menor nas folhas de sombra, com células menores e em menor número.

A proporção relativamente maior de parênquima lacunoso nas folhas sombreadas aumenta a absorção de luz pela folha devido a sua maior dispersão interna (Vogelmann et al., 1996). Nas folhas dorsiventrais, como as do amendoim-forrageiro, o mesofilo lacunoso, com suas células de arranjo irregular e maior proporção de espaços intercelulares, aumenta a distância percorrida pela luz dentro das folhas através de sua reflexão nas interfaces gás/líquido (Lambers et al., 1998). 

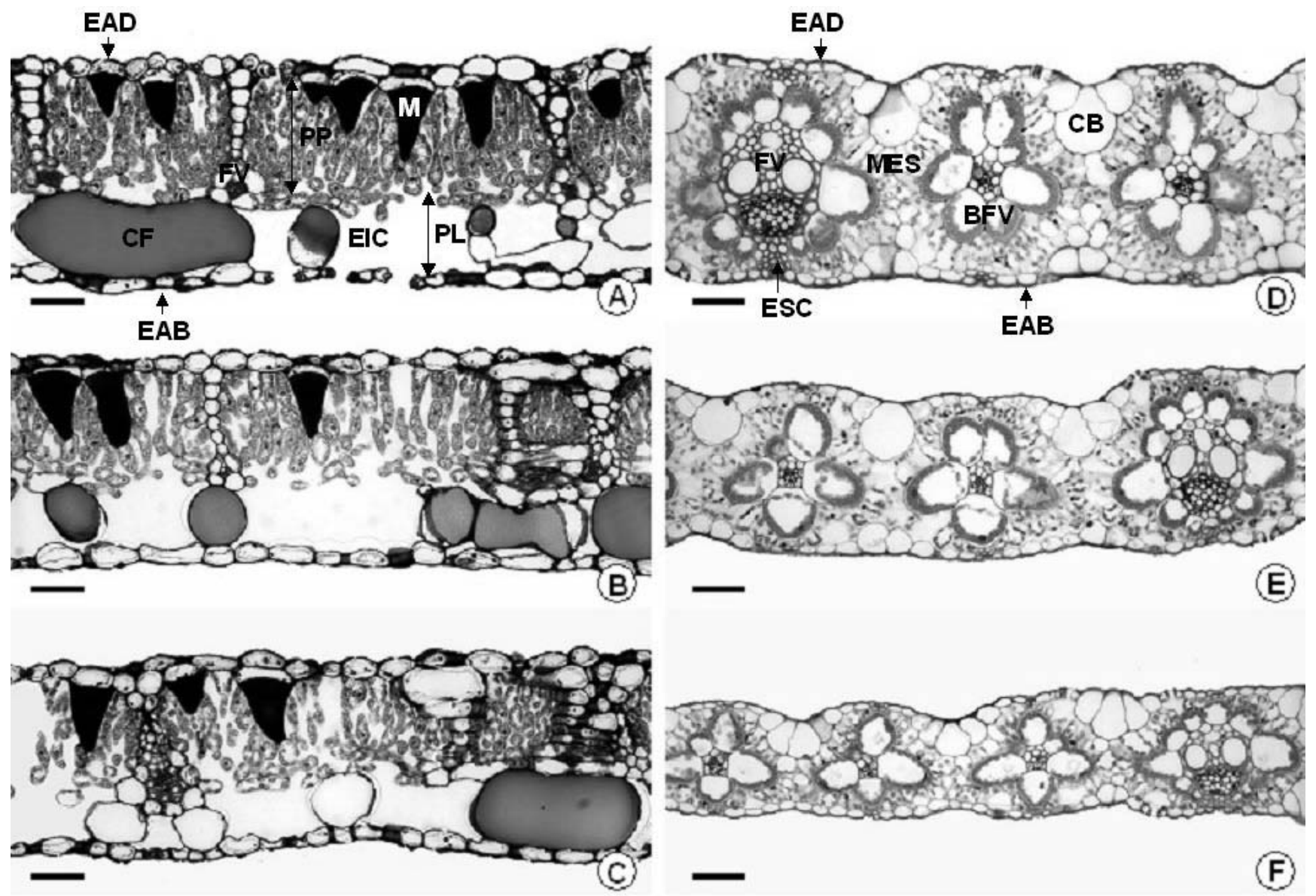

$\mathrm{BFV}=$ bainha do feixe vascular $\mathrm{CB}=$ célula buliforme $\mathrm{CF}=$ idioblasto contendo compostos fenólicos; $\mathrm{EAB}=$ epiderme abaxial; $\mathrm{EAD}=$ epiderme adaxial; $\mathrm{EIC}=$ espaço intercelular; $\mathrm{ESC}=$ esclerênquima; $\mathrm{FV}=$ feixe vascular; $\mathrm{M}=$ idioblasto com mucilagem; $\mathrm{MES}=$ mesofilo; $\mathrm{PL}=$ parênquima lacunoso; $\mathrm{PP}=$ parênquima paliçádico; Barra $=50 \mu \mathrm{m}$.

Figura 1 - Seção transversal de folhas de amendoim-forrageiro (A, B, C) e braquiária (D, E, F) submetidas a três níveis de sombreamento $(0,50$ e $70 \%$, respectivamente).

De acordo com Ivanova \& P'yankov (2002), a maior proporção de parênquima lacunoso representa uma forma de aclimatação da fotossíntese ao sombreamento, uma vez que suas células promovem melhor dispersão da luz. Estas células são adaptadas para absorver luz difusa, cuja proporção é maior na sombra (Healey et al., 1998).

Alterações na espessura da epiderme, volume das células mesofílicas, número de camadas de mesofilo, quantidade de espaços intercelulares no mesofilo, espessura das nervuras ou espessura da parede celular, podem promover modificações na espessura da folha. Da mesma forma, a densidade dos tecidos pode ser afetada por estas variáveis, bem como pelos constituintes citoplasmáticos ou pelas diferentes proporções dos tipos celulares. Assim, alterações em qualquer uma destas características podem simultaneamente alterar tanto a espessura quanto a densidade das folhas (Meziane \& Shipley, 1999).

As alterações na AFE podem ser causadas por variações na espessura da folha e, ou, na densidade de massa foliar $\left(\mathrm{kg} / \mathrm{m}^{3}\right)$ (Witkowski \& Lamont, 1991). Entre as causas para a menor densidade de massa foliar estão a maior proporção de espaços intercelulares na folha e/ou a menor proporção de material denso, como lignina ou tecido esclerenquimático (Van Arendonk \& Poorter, 1994).

O aumento da AFE das folhas de amendoim-forrageiro, apesar da não redução na espessura das folhas pode ser explicado, em parte, pelo incremento linear $(\mathrm{P}<0,05)$ na proporção de espaços intercelulares nas folhas sombreadas, nos dois cortes avaliados (Tabela 1). Isso pode ter contribuído para a redução da densidade de massa foliar, e consequentemente para o aumento da AFE.

A redução da espessura do parênquima paliçádico sob sombra, que implica redução do tamanho e/ou número de suas células, também pode ter contribuído para a diminuição da densidade da folha e maior AFE do amendoim-forrageiro.

De acordo com Terashima et al. (2001), a resistência à difusão de $\mathrm{CO}_{2}$ na folha diminui sua eficiência fotossintética, não apenas por diminuir a concentração de $\mathrm{CO}_{2}$ no interior 
da folha, mas também por aumentar a fotorrespiração. Assim, é vantajoso para a folha minimizar a resistência à difusão de $\mathrm{CO}_{2}$. Nas folhas sob sombra, características como a menor espessura do parênquima paliçádico, o menor número e/ou tamanho das células, bem como a maior proporção de espaços intercelulares, podem representar uma tentativa de diminuir a resistência à difusão de gases $\left(\mathrm{CO}_{2}\right)$ no interior da folha, buscando aumentar sua eficiência fotossintética.

A densidade estomática $\left(\mathrm{n}^{\mathrm{o}}\right.$ de estômatos $\left./ \mathrm{mm}^{2}\right)$ nas faces adaxial e abaxial das folhas de amendoim-forrageiro e braquiária diminuiu linearmente $(\mathrm{P}<0,05)$ com o aumento nos níveis de sombra em todos os cortes avaliados (Tabelas 1 e 2). Em ambas as espécies, o número de estômatos foi maior na epiderme adaxial da folha.

Os resultados obtidos estão de acordo com o que foi observado para outras espécies, onde geralmente se verifica maior densidade estomática com a elevação da irradiância (Wilkinson \& Beard, 1975; Allard et al., 1991; Morais et al., 2004; Lima Junior et al., 2006).

Allard et al. (1991) observaram que, sob baixa irradiância (30\%), a densidade estomática nas folhas de festuca foi 17 ou 24\% menor que sob alta irradiância (pleno sol), com maior redução na epiderme abaxial.

A densidade estomática está relacionada à capacidade fotossintética das folhas, uma vez que, quanto maior o número de estômatos $/ \mathrm{mm}^{2}$, menor a resistência à difusão de gases na folha. Assim, a menor densidade estomática pode contribuir para menor taxa fotossintética das folhas sob sombra (Lima Junior et al., 2006). Contudo, o aumento da área foliar das plantas sombreadas pode compensar, pelo menos em parte, a menor densidade de estômatos.

Nas folhas de amendoim-forrageiro, por exemplo, em ambos os cortes, o número total de estômatos por folíolo, na epiderme adaxial, aumentou em média 21 e $14 \%$ sob 50 e $70 \%$ de sombra, respectivamente. Na epiderme abaxial, o aumento foi de 18 e $26 \%$, no primeiro corte, para as plantas submetidas a 50 e $70 \%$ de sombra, respectivamente.

Apesar do aumento na proporção de espaços intercelulares nas folhas de amendoim-forrageiro (Tabela 1; Figura 1), a área ocupada pelos diferentes tecidos não foi afetada significativamente $(\mathrm{P}>0,05)$ pelo incremento nos níveis de sombra (Tabela 1).

Outros estudos com diferentes espécies confirmam a maior proporção de espaços intercelulares nas folhas sombreadas (Paiva \& Guimarães, 2001; Morais et al., 2004; Lima Junior et al., 2006). Este aumento na proporção de espaços intercelulares facilita a absorção da luz e casualiza sua direção, melhorando sua captação pelos cloroplastos (Ivanova \& P'yankov, 2002).
Nas folhas de braquiária, os níveis crescentes de sombra afetaram a proporção dos diferentes tecidos de forma distinta nos três cortes estudados (Tabela 2). A proporção de mesofilo, esclerênquima, epiderme adaxial e epiderme abaxial nas seções transversais de folha não foi afetada de forma significativa $(\mathrm{P}>0,05)$ pelos tratamentos, em nenhum dos cortes. No trabalho de Allard et al. (1991), no qual os autores avaliaram os efeitos de três níveis de sombra $(0 ; 40$ e $70 \%)$ sobre a anatomia foliar de festuca, verificou-se que as proporções de epiderme, células buliformes, feixes vasculares e mesofilo na seção transversal de folhas foram similares entre os tratamentos.

No primeiro corte, as folhas de braquiária apresentaram aumento quadrático $(\mathrm{P}<0,05)$ na proporção de bainha do feixe vascular (BFV), com o aumento nos níveis de sombra, observando-se maior proporção de BFV nas folhas sob 50\% de sombra.

Deinum et al. (1996) não observaram variação significativa na proporção de BFV nas folhas de Brachiaria brizantha e Panicum maximum var. Trichoglume, submetidas a diferentes níveis de intensidade luminosa.

A bainha do feixe vascular (BFV), característica de gramíneas $\mathrm{C}_{4}$, exerce papel importante no processo fotossintético destas espécies, pois suas células contêm a enzima Rubisco, responsável pela refixação, via ciclo de Calvin, do $\mathrm{CO}_{2}$ inicialmente fixado pela enzima PEPcarboxilase nas células do mesofilo. Este processo em duas etapas, que consiste da assimilação inicial do carbono no mesofilo e na redução fotossintética do carbono na BFV, serve para inibir a fotorrespiração, através da concentração de $\mathrm{CO}_{2}$ no local onde ocorre a enzima Rubisco (Dengler et al., 1994). O aumento do tamanho destas células pode ter por objetivo aumentar a eficiência fotossintética das plantas sob sombra, onde a disponibilidade de luz é limitante para o processo de fixação de carbono.

Nas folhas de braquiária coletadas por ocasião do segundo corte, observou-se redução linear $(\mathrm{P}<0,05)$ da área ocupada pelos feixes vasculares, em função dos níveis crescentes de sombra.

O sombreamento pode causar redução na proporção dos tecidos vascular e de sustentação, além de redução na espessura da parede celular (Buxton \& Casler, 1993; Dickson, 2000; Berlyn \& Cho, 2000). Isto se deve em parte a menor densidade de nervuras devido à expansão da área foliar sob sombra (Dickson, 2000).

A temperatura elevada e o déficit hídrico podem causar aumento na espessura e lignificação da parede celular de plantas cultivadas a pleno sol (Buxton \& Casler, 1993) e de acordo com Van Arendonk \& Poorter (1994) o maior investimento em compostos de parede celular, aumenta a 
resistência das folhas e permite o crescimento sob condições adversas. Como na sombra geralmente se observa menor temperatura e maior teor de umidade no solo (Belsky et al., 1993; Wilson, 1996), isto pode ter contribuído para a redução da proporção de feixes vasculares nas folhas sombreadas em relação às folhas a pleno sol.

Avaliando as respostas anatômicas de duas gramíneas de clima temperado à redução na intensidade de luz, Wilkinson \& Beard (1975) verificaram menor proporção de tecido vascular e de sustentação nas plantas de Poa pratensis submetidas ao sombreamento.

Em estudo realizado por Deinum et al. (1996) as gramíneas tropicais Brachiaria brizantha e Panicum maximum var. Trichoglume, submetidas a diferentes níveis de intensidade luminosa, apresentaram menor número de células esclerenquimáticas, com menor espessura de parede celular, sob baixa luminosidade. Já a proporção de tecido vascular variou pouco em função dos níveis de luz, mas suas células também apresentaram menor espessura de parede celular secundária sob sombra.

A redução quadrática $(\mathrm{P}<0,05)$ na área ocupada pelas células buliformes nas folhas de braquiária em função do sombreamento, no terceiro corte, com menor proporção sob $50 \%$ de sombra, pode estar relacionada com a função que estas células exercem. As células buliformes são células epidérmicas volumosas responsáveis pela função motora de enrolar as folhas (Dickson, 2000), reduzindo a área de transpiração foliar em resposta às condições ambientais (Larcher, 2000). Assim, em ambientes sombreados, com maior disponibilidade de água e menores níveis de irradiância, fatores que contribuem para a menor perda de água por transpiração, a menor proporção de células buliformes se justificaria pelo fato destas células serem menos exigidas.

\section{Conclusões}

As forrageiras Arachis pintoi e Brachiaria decumbens apresentam mudanças na área foliar específica e na anatomia foliar quantitativa quando submetidas ao sombreamento, comprovando a plasticidade anatômica e aclimatação destas espécies às variações na intensidade luminosa.

\section{Referências}

ALLARD, G.; NELSON, C.J.; PALLARDY, S.G. Shade effects on growth of tall fescue: leaf anatomy and dry matter partitioning. Crop Science, v.31, p.163-167, 1991.

BELSKY, A.J.; MWONGA, S.M.; AMUNDSON, R.G. et al. Comparative effects of isolated trees on their undercanopy environment in high- and low-rainfall savannas. Journal of Applied Ecology, v.30, p.143-155, 1993.

BERLYN, G.P.; CHO, J. Light, moisture, and nutrient use by plants. In: ASHTON, M.S., MONTAGNINI, F. (Eds.) The silvicultural basis for agroforestry systems. Boca Raton: CRC Press, 2000. p.9-39.

BJÖRKMAN, O. Responses to different quantum flux densities. In: LANGE, O.L.; NOBEL, P.S.; OSMOND, C.B. et al. (Eds.) Physiological plant ecology $I$ : responses to the physical environment. Berlin: Springer-Verlag, 1981. p.57-107.

BUXTON, D.R.; CASLER, M.D. Environmental and genetic effects on cell wall composition and digestibility. In: JUNG, H.G.; BUXTON, D.R.; HATFIELD, R.D. et al (Eds.) Forage cell wall structure and digestibility. Madison: American Society of agronomy, 1993. p.685-714.

DEINUM, B.; SULASTRI, R.D.; ZEINAB, M.H.J. et al. Effects of light intensity on growth, anatomy and forage quality of two tropical grasses (Brachiaria brizantha and Panicum maximum var. Trichoglume). Netherlands Journal of Agricultural Science, v.44, p.111-124, 1996.

DENGlER, N.G.; DENGLER, R.E.; DONNELLY, P.M. et al. Quantitative leaf anatomy of $\mathrm{C} 3$ and $\mathrm{C} 4$ grasses (Poaceae): bundle sheath and mesophyll surface area relationships. Annals of Botany, v.73, p.241-255, 1994

DICKSON, W.C. Integrative plant anatomy. San Diego: Academic Press, 2000, 533p.

EVANS, J.R.; POORTER, H. Photosynthetic acclimation of plants to growth irradiance: the relative importance of specific leaf area and nitrogen partitioning in maximizing carbon gain. Plant, Cell and Environment, v.24, p.755-767, 2001.

HANDRO, W. Contribuição ao estudo da venação e anatomia foliar das Amarantáceas dos Cerrados. Anais da Academia Brasileira de Ciências, v.36, n.4, p.479-499, 1964.

HEALEY, K.D.; RICKERT, K.G.; HAMMER, G.L. et al. Radiation use efficiency increases when the diffuse component of incident radiation is enhanced under shade. Australian Journal of Agricultural Research, v.49, p.665-672, 1998.

IVANOVA, L.A.; P'YANKOV, V.I. Structural adaptations of the leaf mesophyll to shading. Russian Journal of Plant Physiology, v.49, n.3, p.419-431, 2002.

JOHANSEN, D.A. Plant microtechnique. New York: McGrawHill Book Co. Inc., 1940, 423p.

KEPHART, K.D.; BUXTON, D.R. Forage quality response of C3 and C4 perennial grasses to shade. Crop Science, v. 33, p.831-837, 1993.

LAMBERS, H.; CHAPIM III, F.S.; PONS, T.L. Plant physiological ecology. New York: Springer, 1998. 540p.

LARCHER, W. Ecofisiologia vegetal. São Carlos: RiMa, 2000. $531 \mathrm{p}$.

LIMA JUNIOR, E.C.; ALVARENGA, A.A.; CASTRO, E.M. et al. Aspectos fisioanatômicos de plantas jovens de Cupania vernalis Camb. Submetidas a diferentes níveis de sombreamento. Revista Árvore, v.30, n.1, p.33-41, 2006.

LIN, C.H.; MCGRAW, R.L.; GEORGE, M.F. et al. Nutritive quality and morphological development under partial shade of some forages species with agroforestry potential. Agroforestry Systems, v.59, p.269-281, 2001.

MEZIANE, D.; SHIPLEY, B. Interacting determinants of specific leaf area in 22 herbaceous species: effects of irradiance and nutrient availability. Plant, Cell and Environment, v.22, p.447-459, 1999.

MORAIS, H.; MEDRI, M.E.; MARUR, C.J. et al. Modifications on leaf anatomy of Coffea arabica caused by shade of pigeonpea (Cajanus cajan). Brazilian Archives of Biology and Technology, v.47, n.6, p.863-871, 2004.

O'BRIEN, T.P.; FEDER, N.; McCULLY, M.E. Polychromatic staining of plant cell walls by toluidine blue O. Protoplasma, v. 59, n.2, p.368-373, 1964. 
PAIVA, L.C.; GUIMARÃES, R.J. Efeitos dos níveis de irradiância sobre a anatomia foliar de mudas de cafeeiro (Coffea arabica L.). In: CONGRESSO BRASILEIRO DE PESQUISAS CAFEEIRAS, 27., 2001. p.110-112.

STATISTICAL ANALYSIS SYSTEM - SAS. SAS/STAT User's Guide. Version 6. 4.ed., V.1, Cary: SAS Institute Inc., 1990. 943p.

TERASHIMA, I.; MIYAZAWA, S.; HANBA, Y. Why are sun leaves thicker than shade leaves? - Consideration based on analyses of $\mathrm{CO}_{2}$ diffusion in the leaf. Journal of Plant Research, v.114, p.93-105, 2001

VAN ARENDONK, J.J.C.M.; POORTER, H. The chemical composition and anatomical structure of leaves of grass species differing in relative growth rate. Plant, Cell and Environment, v.17, p.963-970, 1994.

VOGELMAN, T.C.; NISHIO, J.N.; SMITH, W.K. Leaves and light capture: light propagation and gradients of carbon fixation within leaves. Trends in Plant Science, v.1, p.65-70, 1996.

WILKINSON, J.F.; BEARD, J.B. Anatomical responses of "Merion" Kentucky Bluegrass and "Pennlawn" Red Fescue at reduced light intensities. Crop Science, v.15, p.189-194, 1975.

WILSON, J.R. Shade-stimulated growth and nitrogen uptake by pastures grasses in a subtropical environment. Australian Journal of Agricultural Research, v.47, p.1075-1093, 1996. WITKOWSKI, E.T.F.; LAMONT, B.B. Leaf specific mass confounds leaf density and thickness. Oecologia, v.88, p.486-493, 1991. 